\title{
Left ventricular thrombectomy in a cocaine user with normal coronary arteries
}

\author{
S. Fortier, MD, ${ }^{a}$ R. G. Demaria, MD, PhD, ${ }^{a, c}$ G. B. Pelletier, MD, ${ }^{b}$ M. Carrier, $M D,{ }^{a}$ and L. P. Perrault, MD, PhD, ${ }^{a}$ \\ Montreal, Quebec, Canada, and Montpellier, France
}

$\mathrm{F}$

ormation of a left ventricular (LV) thrombus may follow an anterior acute myocardial infarction (AMI) and is associated with a significant risk of systemic embolization. ${ }^{1}$ A 37 -year-old man was seen at a referring hospital with acute ischemia of the right lower limb with pain, paresthesia, and paresis. There was a history of cocaine use by inhalation, with description of anginal pain during bouts of drug use and a more sustained episode of thoracic pain about 4 months before admission. There were no signs or symptoms of congestive heart failure. A successful right femoral thrombectomy was performed with general anesthesia, and intravenous heparin therapy was instituted. The electrocardiogram on admission revealed an anteroseptal myocardial infarction of undetermined date. A transthoracic echocardiogram was performed to identify the source of embolism and revealed a severe $\mathrm{LV}$ dysfunction with an ejection fraction of $30 \%$. The transesophageal echocardiogram showed an apical mural thrombus with a large, pedunculated, mobile, heterogeneous mass floating in the LV (Figure 1). A coronary angiogram was done before the operation and showed no significant coronary artery stenosis.

Because of the risk of embolization as a result of the mobile nature and the size of the thrombus, surgical treatment was proposed. After median sternotomy and establishment of cardiopulmonary bypass with double caval cannulation, the aorta was crossclamped and tepid antegrade blood cardioplegia was administered before any manipulation of the heart. A left atriotomy was performed, and the mitral valve was explored. Thrombi were aspirated, and there were no signs of infection. All mobile parts were excised. Video-assisted exploration was performed to ascertain complete thrombus excision, although the access to the apex was difficult. The LV cavity was then washed out extensively with warm saline solution and débrided. The crossclamp time was 36 minutes, and the total cardiopulmonary bypass time was $50 \mathrm{~min}-$ utes. Postoperative transesophageal echocardiography showed complete excision except for the mural (Figure 2). Heparin therapy

\footnotetext{
From the Departments of Surgery ${ }^{\mathrm{a}}$ and Cardiology, ${ }^{\mathrm{b}}$ Montreal Heart Institute, Montreal, Quebec, Canada, and the Cardiovascular Surgery Unit, Arnaud de Villeneuve Teaching Hospital, Montpellier, France.

Received for publication April 18, 2002; accepted for publication May 1, 2002.

Address for reprints: L. P. Perrault, MD, PhD, Research Center, Montreal Heart Institute, 5000 Belanger St E, Montreal, Quebec, Canada H1T 1C8 (E-mail: lpperrau @icm.umontreal.ca).

J Thorac Cardiovasc Surg 2003;125:204-5

Copyright $\odot 2003$ by The American Association for Thoracic Surgery $0022-5223 / 2003 \$ 30.00+0$

doi: $10.1067 / \mathrm{mtc} .2003 .118$
}

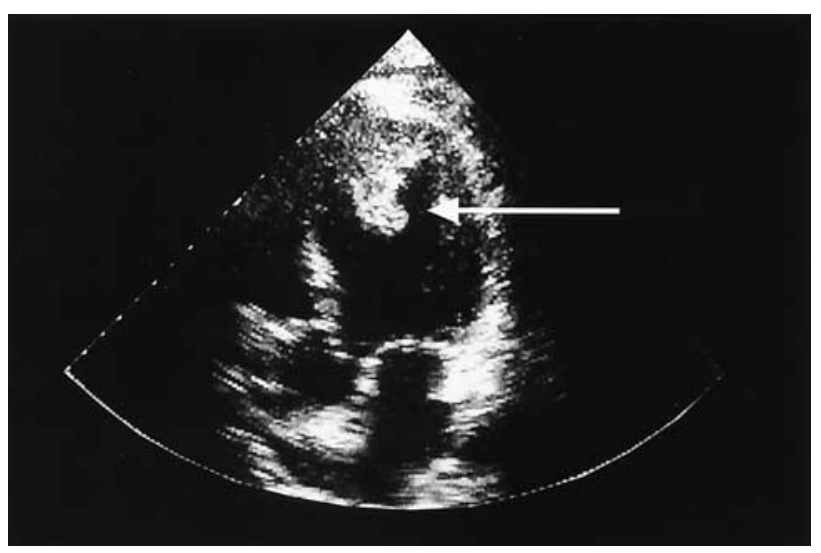

Figure 1. Preoperative transesophageal echocardiogram demonstrating echodense mass at LV apex (arrow).

without bolus administration was restarted 4 hours after the operation to prevent the recurrence of thrombi. The patient was operated on again the next morning for bleeding from the left atriotomy without hemodynamic instability, and the ensuing postoperative course was uneventful. The microscopic examination of the thrombus revealed an accumulation of fibrin, platelets, and red cells. The patient was discharged 7 days after the surgery with a 6-month course of oral anticoagulant therapy.

\section{Comments}

The first report of an association between cocaine use and AMI was in $1982 .{ }^{2}$ The risk is increased 24 times in the first 60 minutes after cocaine use, and this is unrelated to the amount ingested. ${ }^{2}$ The exact incidence of AMI among cocaine users is unknown, but about $6 \%$ of patients who arrive at the emergency department with cocaine-induced retrosternal pain have enzymatic evidence of AMI. ${ }^{2}$ The formation of a ventricular thrombus after AMI is common no matter the cause, despite therapeutic anticoagulation. ${ }^{1}$ Also, ventricular thrombi usually appear after anterior AMI and early in its course, with considerable chances of systemic embolization depending on the morphologic appearance. ${ }^{3}$

Few reports have been published about LV thrombus associated with cocaine-induced AMI, ${ }^{4,5}$ but intracavitary cardiac evaluation is required even when no sign of embolization is present, because cocaine is associated with platelet activation, formation of platelets, and thrombosis promotion. ${ }^{6}$ Postinfarction LV thrombi are at risk of embolization, especially if they are mobile and pedunculated, ${ }^{3}$ as was demonstrated in our case with a clear episode of right lower limb ischemia. A role for systemic anticoagulation and thrombolysis has already been demonstrated, but this may sometimes lead to the formation of an unstable thrombus, 


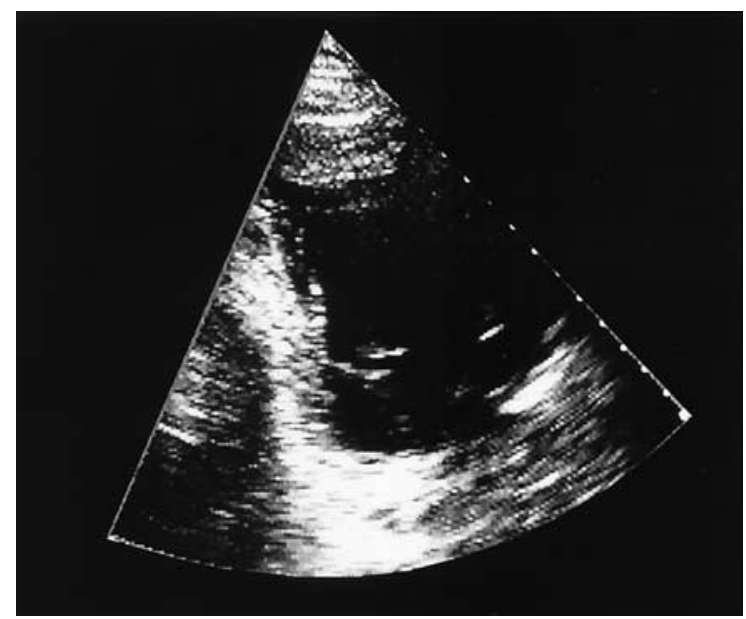

Figure 2. Postoperative transesophageal echocardiographic result.

emphasizing the need of a close echocardiographic and surgical follow-up. ${ }^{7}$

The indications for surgical thrombectomy are an episode of systemic or coronary embolization or a change in the morphologic features. ${ }^{7,8}$ Different surgical techniques have been described, such as left ventriculotomy, ${ }^{8}$ transaortic video-assisted, ${ }^{9}$ and left atrial $^{3}$ approaches. Video-assisted techniques can be useful to facilitate exposure of the inner LV and confirm complete excision of the thrombus. Importantly, techniques that avoid ventriculotomy allow preservation of the LV function and a better postoperative course.

With a history of systemic embolization in a patient who uses cocaine, transesophageal echocardiographic evaluation is manda- tory to excluded LV thrombus. Although anticoagulation is required, surgical thrombectomy is the sole treatment that will avoid recurrence. Video-assisted techniques are especially helpful in the presence of ventricular dysfunction when ventriculotomy would compromise LV function, as was the case here with a reduced LV ejection fraction related to previous AMI.

\section{References}

1. Visser CA, Kan G, Meltzer RS, Dunning AJ, Roelandt J. Embolic potential of left ventricular thrombus after myocardial infarction: a two-dimensional echocardiographic study of 119 patients. J Am Coll Cardiol. 1985;5:1276-80.

2. Lange RA, Hillis LD. Cardiovascular complications of cocaine use. N Engl J Med. 2001;345:351-8.

3. Early GL, Ballenger M, Hannah H 3rd, Roberts SR. Simplified method of left ventricular thrombectomy. Ann Thorac Surg. 2001;72: 953-4.

4. Sauer CM. Recurrent embolic stroke and cocaine-related cardiomyopathy. Stroke. 1991;22:1203-5.

5. Espinola-Zavaleta NG, Vargas-Barron J, Vazquez-Neira J, RomeroCardenas A, Keirns C. Echocardiographic diagnosis of biventricular thrombi in a cocaine-induced myocardial infarction. Echocardiography. 1998;15:499-502.

6. Benzaquen BS, Cohen V, Eisenberg MJ. Effects of cocaine on the coronary arteries. Am Heart J. 2001;142:402-10.

7. Glickson M, Agranat O, Ziskind Z, Kaplinski E, Vered Z. From swirling to a mobile pedunculated mass - the evolution of left ventricular thrombus despite full anticoagulation. Chest. 1993;103:281-3.

8. Nili M, Deviri E, Jortner R, Strasberg B, Levy MJ. Surgical removal of a mobile, pedunculated left ventricular thrombus: report of 4 cases. Ann Thorac Surg. 1988;46:396-400.

9. Tsukube T, Okada M, Ootaki Y, Tsuji Y, Yamashita C. Transaortic video-assisted removal of a left ventricular thrombus. Ann Thorac Surg. 1999;68:1063-5. 